\title{
Effects of the thermal environment on the temporal pattern of emergence of hatchling loggerhead turtles Caretta caretta
}

\author{
Kathleen L. Moran*, Karen A. Bjorndal, Alan B. Bolten \\ Archie Carr Center for Sea Turtle Research and Department of Zoology, University of Florida, PO Box 118525, \\ Gainesville, Florida 32611, USA
}

\begin{abstract}
Sea turtles deposit their eggs in beaches at a depth of about $50 \mathrm{~cm}$ and leave them to incubate for approximately $60 \mathrm{~d}$. After that time, hatchlings emerge from the sand at night, both to avoid predation and to prevent overheating. Three hypotheses have been proposed regarding the thermal cues involved in emergence. Hatchlings emerge (1) after sand temperature falls below a critical threshold, (2) after a negative thermal gradient in the sand above the nest has been created, making upper sand cooler than sand below, or (3) in response to a rapid decrease in the temperature of the nest column. This study evaluated the cue(s) that loggerhead sea turtle Caretta caretta hatchlings use to emerge into a safe thermal environment. We collected thermal data at 5 depths in the sand from 150 loggerhead nests that had been relocated in Broward County, Florida. Hatchlings had a significant effect on sand temperatures due to metabolic heat. Therefore, to evaluate thermal cues, temperatures should be measured in nest columns and not adjacent to nests, as in previous studies. A critical threshold temperature existed, above which hatchlings did not emerge. The threshold temperature at $0 \mathrm{~cm}$ was $32.4^{\circ} \mathrm{C}$, which is similar to upper thermal thresholds of swimming activity for loggerhead and green turtle Chelonia mydas hatchlings measured in other studies. Most hatchlings emerged after a reversal in the thermal gradients between sand depths, but no particular temperature differential existed between those depths that cued emergence. A delay occurred after both threshold and reversal cues before hatchlings emerged, which may protect hatchlings under rapidly changing environmental conditions. Most hatchlings emerged sooner after the threshold temperature had been reached than after the temperature gradient had been reversed, but the 2 cues cannot be completely distinguished without further research. Rate of temperature decline was not a cue because most hatchlings emerged when rates were close to zero. We conclude that the critical threshold temperature is the most probable cue and that the most probable mechanism for controlling time of emergence is physiologi$\mathrm{cal}$ - that is, a thermal inhibition of coordinated muscle movement so that emergence from the sand is only possible below a critical temperature threshold. Emergence data from in situ nests support these thermal patterns in relocated nests. These results have important implications for management of beach habitat for nesting sea turtles. Human impacts, such as beach renourishment and beach-front development, can change the thermal characteristics of the nesting environment, and therefore affect temporal emergence patterns of hatchlings.
\end{abstract}

KEY WORDS: Caretta caretta - Loggerhead sea turtle ' Hatchling emergence Thermal cue - Physiological response

\section{INTRODUCTION}

Emergence from the nest is the culmination of development and hatching in many oviparous organisms. The time of day at which emergence occurs varies among organisms. However, nocturnal emergence is

•E-mail:kmoran@zoo.ufl.edu crucial to the survival of most sea turtle hatchlings for several reasons. Surface-sand temperatures during the day can be fatal to hatchlings because they cannot regulate their body temperature in such extreme conditions. High temperatures can also lower activity levels of hatchlings (Mrosovsky 1968) at a time when they are most visible to terrestrial predators, particularly birds (Stancyk 1982) 
Despite the danger of a daytime emergence, sea turtle hatchlings sometimes do complete their ascent from the nest to the surface of the sand during the day (Balazs \& Ross 1974). In such cases, hatchlings usually reach the top few centimeters of sand and pause (Caldwell 1959, Bustard 1967), presumably waiting for favorable conditions before beginning their run to the sea. Because timing of emergence is so important, hatchlings may use a series of environmental cues to guide their emergence. These cues are almost certainly temperature related (Bustard 1967, Mrosovsky 1968, Witherington et al. 1990, Hays et al. 1992, Gyuris 1993), although visual cues may be useful to hatchlings that pause at the very surface of the sand. Hatchlings probably do not depend solely on the absence of light to emerge because some daytime emergences do occur, especially after heavy rains.

Three hypotheses have been proposed regarding the cues that hatchlings use to time their emergence. The first hypothesis is that hatchlings emerge only after sand temperatures fall below a critical threshold (Hendrickson 1958, Mrosovsky 1968, Bustard 1972). Three critical temperatures have been proposed for green turtle Chelonia mydas hatchlings: $33^{\circ} \mathrm{C}$ in Malaya and Sarawak (Hendrickson 1958), $28.5^{\circ} \mathrm{C}$ in Surinam (Mrosovsky 1968), and $31^{\circ} \mathrm{C}$ in Australia (Bustard 1972). No information is available on the critical temperatures for emerging loggerhead Caretta caretta hatchlings, but O'Hara (1980) determined an upper threshold of $33.0^{\circ} \mathrm{C}$ for coordinated swimming activity in loggerhead hatchlings.

The second hypothesis is that hatchlings waiting in the sand are negatively thermotaxic (Gyuris 1993). According to this hypothesis, hatchlings emerge after a negative thermal gradient develops in the sand column above the nest (i.e. surface-sand temperature is cooler than that below). Normally, sand is much warmer at the surface than below during the day. As the sun sets, the temperature of surface sand drops rapidly and falls below that of deeper sand, which cools more slowly.

The third hypothesis is that hatchlings emerge after temperature rapidy decreases in the nest column (Witherington et al. 1990). A rapid decrease in sand temperature might stimulate an earlier hatchling emergence than a slow decrease (Hays et al. 1992).

When testing thermal hypotheses about hatchling emergence, the amount of metabolic heat in the nest column and distribution of pre-emergent hatchling groups are critical in determining the appropriate location at which to measure temperature and the depths at which thermal cues play a role in hatchling emergence. Hatchlings generate metabolic heat in the nest (Maloney et al. 1990, Godfrey et al. 1997), but no information is available on the extent to which hatchlings raise sand temperature in the nest column immediately prior to emergence. Orientation of hatchlings as they ascend through the sand (Carr \& Ogren 1960) and shape of hatchling groups as they pause near the surface before emerging are poorly known.

In this study, we evaluated the specific thermal cue(s) that trigger loggerhead hatchling emergence by correlating timing of emergence with thermal environment at various depths in the sand above nests. We quantified the thermal effect of hatchlings in the nest neck prior to and during emergence and characterized dimensions and orientations of pre-emergent hatchling groups.

\section{MATERIALS AND METHODS}

Study site. Field work was conducted in Broward County, Florida, USA. Loggerhead nests were marked at 4 protected sites in the Ft. Lauderdale metropolitan area $\left(26.0^{\circ}\right.$ to $\left.26.3^{\circ} \mathrm{N}, 80.2^{\circ} \mathrm{W}\right)$. This area has been extensively developed for human use, and most stretches of beach have heavy pedestrian traffic and are brightly lit. Because sea turtle hatchlings become disoriented and suffer increased mortality on artificially lit beaches, all nests deposited in Broward County are relocated to areas where they are monitored daily throughout incubation. Relocated nests were buried at least $1 \mathrm{~m}$ apart into sand from the beach in which they were originally deposited, and the location of each nest was marked. Employees, through intensive training, recreated natural nest dimensions as closely as possible.

Analysis of thermal regime in nests. Placement and monitoring of thermocouples: Five thermocouples (Copper/Constantan Connectors SMP-T-M/F and Teflon Neoflon PFA High Performance Wire TT-T-245, Omega Engineering Inc., Stamford, CT) were attached to a length of PVC pipe that had been cut in half lengthwise. Holes were drilled at $5 \mathrm{~cm}$ intervals in the pipe, which was $30 \mathrm{~cm}$ long and $1.3 \mathrm{~cm}$ in external diameter. The ends of the thermocouples were inserted through the holes, and the rest of the thermocouple was fastened along the pipe with tape.

One pipe was inserted into the sand in the neck of a nest with thermocouples at depths of $0,5,10,15$, and $20 \mathrm{~cm}$ approximately 24 to $48 \mathrm{~h}$ before emergence was expected. In addition, one pipe was inserted approximately $0.5 \mathrm{~m}$ from the neck of the nest as an adjacent array. Because of the distribution of nests, several nests shared each adjacent array.

We read thermocouples using a digital thermometer (HH-25TC, Omega Engineering Inc., Stamford, CT), with a range of -80 to $199.9^{\circ} \mathrm{C}$, a resolution of $0.1^{\circ} \mathrm{C}$, and an accuracy of $\pm\left(0.4 \%+0.6^{\circ} \mathrm{C}\right)$. The male end of 
each thermocouple was stored in a film canister, and the 5 canisters of each array were protected in a plastic bag. We read each thermocouple in an array every 15 min. Daily monitoring of nests began between 16:45 and 18:00 h, when gradient reversals occurred in the upper layers of sand. Nests that were expected to emerge were monitored each night until at least midnight; all of the cues under investigation had occurred well before that time

To ensure consistent temperature readings, we calibrated each array of thermocouples every time it was removed from the sand. Each thermocouple was suspended in water and its reading was compared with that of an NBS-certified mercury thermometer, accurate to $\pm 0.01^{\circ} \mathrm{C}$ between 27 and $35^{\circ} \mathrm{C}$ (serial no. 7F7747, Parr Instrument Company, Moline, IL). For each thermocouple, a reading was taken on each of the 4 digital thermometers in use on the beach. Each evening, we noted which nests were monitored with which digital thermometer. Neck and adjacent temperature data from each nest were adjusted, based on daily calibration data.

Monitoring of emergences: Emergences from 150 nests in the study took place from 15 June to 11 August 1997. Beginning and ending times of each emergence were recorded, as was the number of hatchlings that emerged. An emergence was defined as any group of 10 or more hatchlings emerging continuously (Witherington et al. 1990). In the event of emergences over multiple nights, only the first emergence from each nest was monitored. As hatchlings emerged, they were placed in a $20 \mathrm{l}$ plastic bucket and released according to Broward County guidelines. We recorded temperatures until 15 to $30 \mathrm{~min}$ after the emergence had ended.

Data analyses: Effect of hatchlings on temperature in the nest neck was determined by comparing neck and adjacent temperatures at corresponding times and depths. We conducted paired sample t tests on neck and adjacent temperatures for each depth at the time of emergence. Because of metabolic heat produced by hatchlings in the nest neck, neck temperatures were used to analyze thermal cues.

Temperatures at the exact time of emergence in the neck array were interpolated from temperatures recorded at the beginning and end of the 15 min interval during which emergence occurred. A histogram was constructed showing the number of emergences that occurred at each temperature for each depth. The critical threshold temperature for emergence was determined by split-line regression (Yeager \& Ultsch 1989) that calculates the transition point between slopes of 2 regression lines. We defined the threshold temperature as the temperature above which emergence by most hatchlings was inhibited.
Times of gradient reversals between pairs of depths $(0$ and $5 \mathrm{~cm}, 0$ and $10 \mathrm{~cm}$, and 5 and $10 \mathrm{~cm}$ ) in the nest neck were designated as the earlier boundary of the 15 min period in which the reversal occurred. These pairs of depths, with ranges of only 5 and $10 \mathrm{~cm}$, were chosen to standardize our results with those of other studies (Mrosovsky 1968, Witherington et al. 1990, Gyuris 1993) and because loggerhead hatchlings, with mean straight carapace lengths of $4.5 \mathrm{~cm}$ (Dodd 1988), could not individually sense temperatures between a range of depths greater than the length of their bodies from head to flipper. Because most hatchlings waited in the top $10 \mathrm{~cm}$ of sand, gradient reversals between these pairs of depths were the most likely candidates for use in emergence. Histograms of emergence patterns in relation to gradient reversal were plotted.

Rate of temperature decline at a depth of $5 \mathrm{~cm}$ in the nest neck was calculated for 15, 30, 60, and 120 min prior to emergence. The temperature reading taken at the interval closest to the actual time of emergence was designated as the temperature at the time of emergence. The relationship between rate of temperature decline and emergence was evaluated visually.

Data analyses were conducted using SPSS software version 7.5 and Microsoft Excel 97 . In all cases, alpha = 0.05 .

Pre-emergent hatchling groups. Sizes and shapes of pre-emergent groups of hatchlings were assessed at night in 15 nests on Hillsboro Beach, FL, from 18 July to 13 August 1997 . Waiting hatchlings, which were not monitored with thermocouple arrays, were visible in these nests. Number of visible turtles in the group was recorded as was length, width, and depth of any depression in the sand above the nest. Sand was brushed away in a wide circle from around the turtles, and sand was removed from one side of the group. Length, width, and depth of the group were measured, and positions, orientations, and total number of hatchlings in the group were recorded.

\section{RESULTS}

Thermal data were collected from 150 emergences, which occurred between 17:40 and 01:04 h and involved between 10 and 115 hatchlings. Timing of emergence was not affected by hatchling group size $(p=0.771$, Pearson $r=-0.024, n=150)$. Similarly, size of the first emergence was not related to total number of eggs in the clutch $(\mathrm{p}=0.456, \mathrm{r}=0.062, \mathrm{n}=148)$. Larger clutches did not produce larger first groups of hatchlings.

The relationship between group size and emergence duration was weak but significant (slope $=0.020$, $p=0.049$, Pearson $r=0.161, n=150$ ). Larger groups of 
Table 1. Number of hatchlings in a group, number of visible hatchlings in a group, depression dimensions $(\mathrm{cm})$, and hatchling group dimensions $(\mathrm{cm})$ from 15 nests in Broward County, Florida, 1997

\begin{tabular}{|lcccc|}
\hline & $\begin{array}{c}\text { No. of nests } \\
\text { observed }\end{array}$ & Mean & $\begin{array}{c}\text { Standard } \\
\text { deviation }\end{array}$ & Range \\
\hline No. of hatchlings in group & 15 & 26.7 & 21.2 & $6-66$ \\
Visible hatchlings in group & 15 & 9.8 & 8.6 & $2-35$ \\
Depression length & 10 & 15.4 & 13.9 & $0-31.0$ \\
Depression width & 10 & 14.4 & 13.1 & $0-31.0$ \\
Depression depth & 15 & 4.8 & 3.9 & $0-10.5$ \\
Hatchling group length & 15 & 14.5 & 7.4 & $6.0-30.5$ \\
Hatchling group width & 15 & 12.6 & 7.5 & $4.5-30.5$ \\
Hatchling group depth & 15 & 16.7 & 7.4 & $7.5-32.0$ \\
\hline
\end{tabular}

gence, possibly because some hatchling groups waited very close to the surface for more than $2 \mathrm{~h}$ before they emerged. Mean temperatures in the neck at 15, 10, and $5 \mathrm{~cm}$ rose, in that order, as hatchlings approached the surface from the nest chamber.

Results of timing of emergences relative to thermal cues are shown in Figs. 2 to 6. Most hatchlings did not emerge immediately after either the threshold was reached or the gradient reversal occurred. Only at 0 and $5 \mathrm{~cm}$ and 0 and $10 \mathrm{~cm}$ did all emergences occur after the reversal. A rapid rate of temperature decline did not occur at any depth within the $2 \mathrm{~h}$ prior to emergence; in fact, many rates of

hatchlings took longer to emerge. However, group size was negatively related to emergence duration per hatchling ( $\mathrm{p}<0.001, \mathrm{r}=-0.479, \mathrm{n}=150)$, indicating that larger groups of hatchlings took less time per hatchling to emerge. This quicker emergence of individual hatchlings in larger groups may reflect social facilitation; that is, through group action, individuals can exit the nest more rapidly.

Variations in dimensions and numbers of waiting hatchling groups revealed significant relationships (Table 1). A significant positive relationship existed between group size and number of visible hatchlings in the waiting group ( $\mathrm{p}=0.009$, Pearson $\mathrm{r}=0.648$, $\mathrm{n}=15$ ). However, there were no significant relationships between group size and any dimensions of the sand depression in the nest neck: length $(\mathrm{p}=0.406, \mathrm{r}=-0.296, \mathrm{n}=10)$, width $(\mathrm{p}=0.476$, $r=-0.255, \mathrm{n}=10)$, or depth $(\mathrm{p}=0.461$, $r=-0.206, n=15$ ). Both length of hatchling group ( $p<0.001, r=0.838, n=15)$ and group width $(p=0.001, r=0.776, n=15)$ were positively related to group size, but not group depth ( $p=0.311, r=0.280, n=15)$. Therefore, as group size increases, hatchlings ascend as close to the surface as possible, thus creating a wide, shallow mass from which they can escape quickly.

Hatchlings raise the mean temperature at each depth in the nest neck prior to emergence (Fig. 1). At the time of emergence, mean temperature at each of the 5 depths was significantly higher (paired sample t-tests, $p<0.001, \mathbf{n}=149$ or 150 ) in the neck array than in the adjacent array. During the $2 \mathrm{~h}$ prior to emergence, mean temperature at $20 \mathrm{~cm}$ remained most constant, but increased first due to hatchlings moving to the surface from the nest chamber. At $0 \mathrm{~cm}$, mean neck temperatures were warmer than those adjacent to the nest during the entire $2 \mathrm{~h}$ before emer- decline were negative, denoting an increase in temperature as hatchlings approached or waited at the surface. At most depths and time periods, rates of decline clustered around $0^{\circ} \mathrm{C} \mathrm{h}^{-1}$, indicating very small rates of change prior to emergence. Hatchlings may have delayed their emergence after both the threshold and gradient reversal because of the very slow decline in temperature immediately prior to emergence. Because temperatures decrease so slowly, hatchlings may emerge in response to a temperature that is only slightly lower than the threshold, but may still not react very quickly in terms of time.

All correlations between temperatures at each pair of depths from 0 to $20 \mathrm{~cm}$ were highly significant

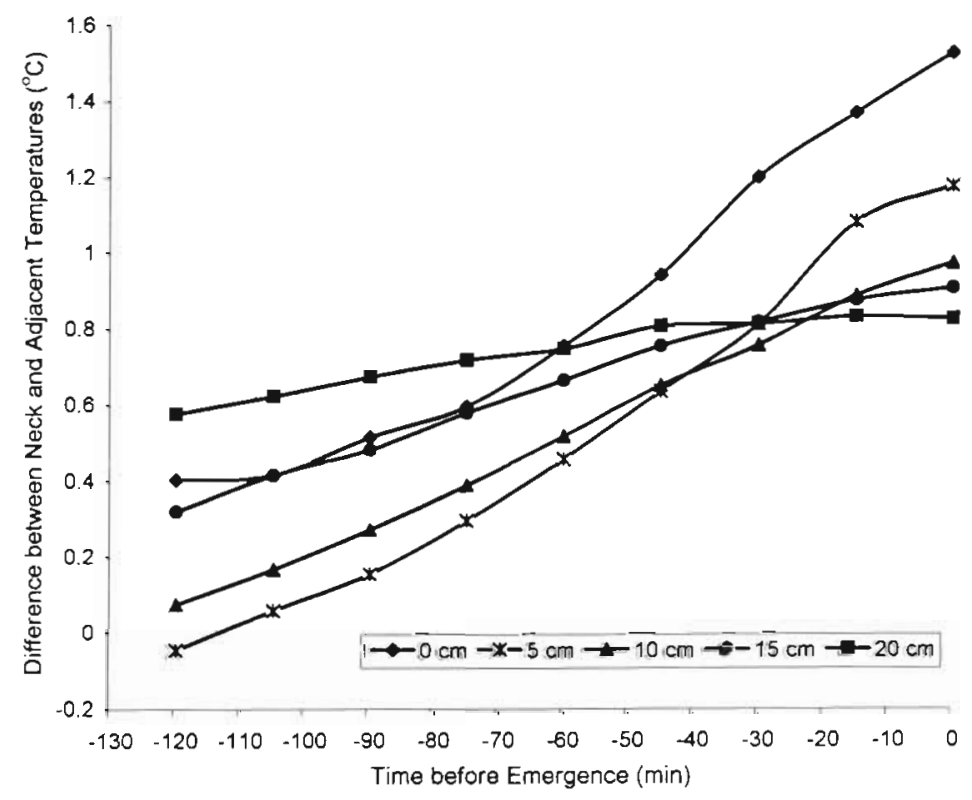

Fig. 1. Mean difference between neck and adjacent temperatures at 0,5 , 10.15 , and $20 \mathrm{~cm}$ for 9 intervals prior to and during emergence in 150 loggerhead nests laid in Broward County, Florida in 1997. Values $>0$ indicate that neck temperatures are warmer than adjacent temperatures 
( $\mathrm{p}<0.001$ ), but Pearson's r values ranged from 0.394 (between 0 and $20 \mathrm{~cm}$ ) to 0.971 (between 15 and $20 \mathrm{~cm}$ ). Temperatures at 0 and $5 \mathrm{~cm}$ varied more than those at greater depths, due to both environmental changes and activity of waiting hatchlings. Because temperatures at different depths are closely correlated, temperature cues at one depth are representative of those at other depths.

\section{DISCUSSION}

\section{Thermal emergence cues}

\section{Group shape and thermal impact \\ of pre-emergent hatchlings}

Both position of waiting hatchlings and effect of metabolic heat from hatchlings must be considered when evaluating thermal cues. Sizes and shapes of hatchling groups, as well as orientation of hatchlings within those groups, determine the depths at which hatchlings wait. Most hatchlings that we observed waited within the top $10 \mathrm{~cm}$ of sand prior to emergence and were oriented vertically as they waited. Because larger numbers of hatchlings formed waiting groups of greater diameter, but not necessarily of greater depth, many hatchlings near the surface may initiate emergence. Upper, middle, or lower hatchlings in a group may sense and respond to thermal cues. As they waited to emerge, hatchlings experienced slightly different thermal regimes, depending on their proximity to the surface, which may have contributed to the temporal variation in hatchling responses to thermal cues. Because hatchlings raise the temperature within the upper $20 \mathrm{~cm}$ of sand due to metabolic activity, temperatures adjacent to the nest may not accurately represent the thermal environment experienced by hatchlings.

\section{Critical threshold}

Evaluation of the histograms reveals that a threshold temperature is a probable cue. At a depth of $0 \mathrm{~cm}$, the number of emergences significantly increased below the threshold temperature $\left(32.4^{\circ} \mathrm{C}\right)$, indicating that a thermal threshold does exist above which hatchlings do not emerge. Emergences, in most cases, did not immediately follow the thresh- old and some emergences occurred well after the threshold. We offer 2 explanations for these delays. First, some delay between the cue and emergence would result from variation in the physiological response of waiting hatchlings to the cue and may protect hatchlings in rapidly changing environmental conditions. Second, and probably most importantly, some hatchling groups arrived at the surface well after the threshold temperature occurred and thus would emerge immediately, at lower temperatures. We can dismiss an effect of seasonal temperature changes on the distribution in Fig. 2 because there was no seasonal effect on temperature at $10 \mathrm{~cm}$ at time of emergence in
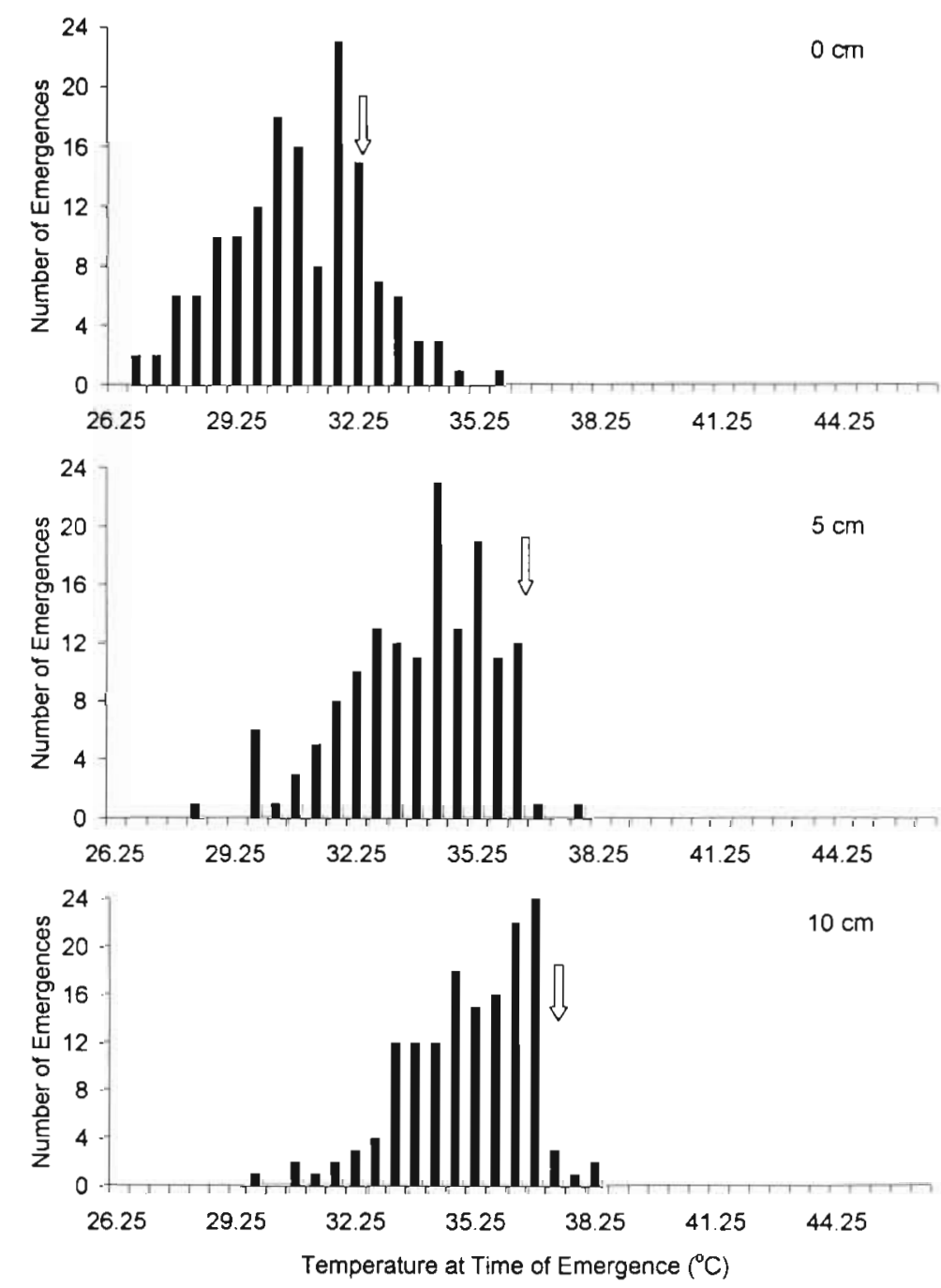

Fig. 2. Relationship between temperatures at 0,5 , and $10 \mathrm{~cm}$ in the nest neck and number of emergences occurring at each temperature $(n=150)$. Arrows indicate critical temperatures $\left(32.4^{\circ} \mathrm{C}\right.$ at $0 \mathrm{~cm}, 36.4^{\circ} \mathrm{C}$ at $5 \mathrm{~cm}$, and $37.4^{\circ} \mathrm{C}$ at $10 \mathrm{~cm}$ ) determined by split-line regression (Yeager \& Uitsch 1989 ) below which the number of emergences significantly increases. The $x$-axis represents the full range of temperatures measured at 0,5 , and $10 \mathrm{~cm}$ 

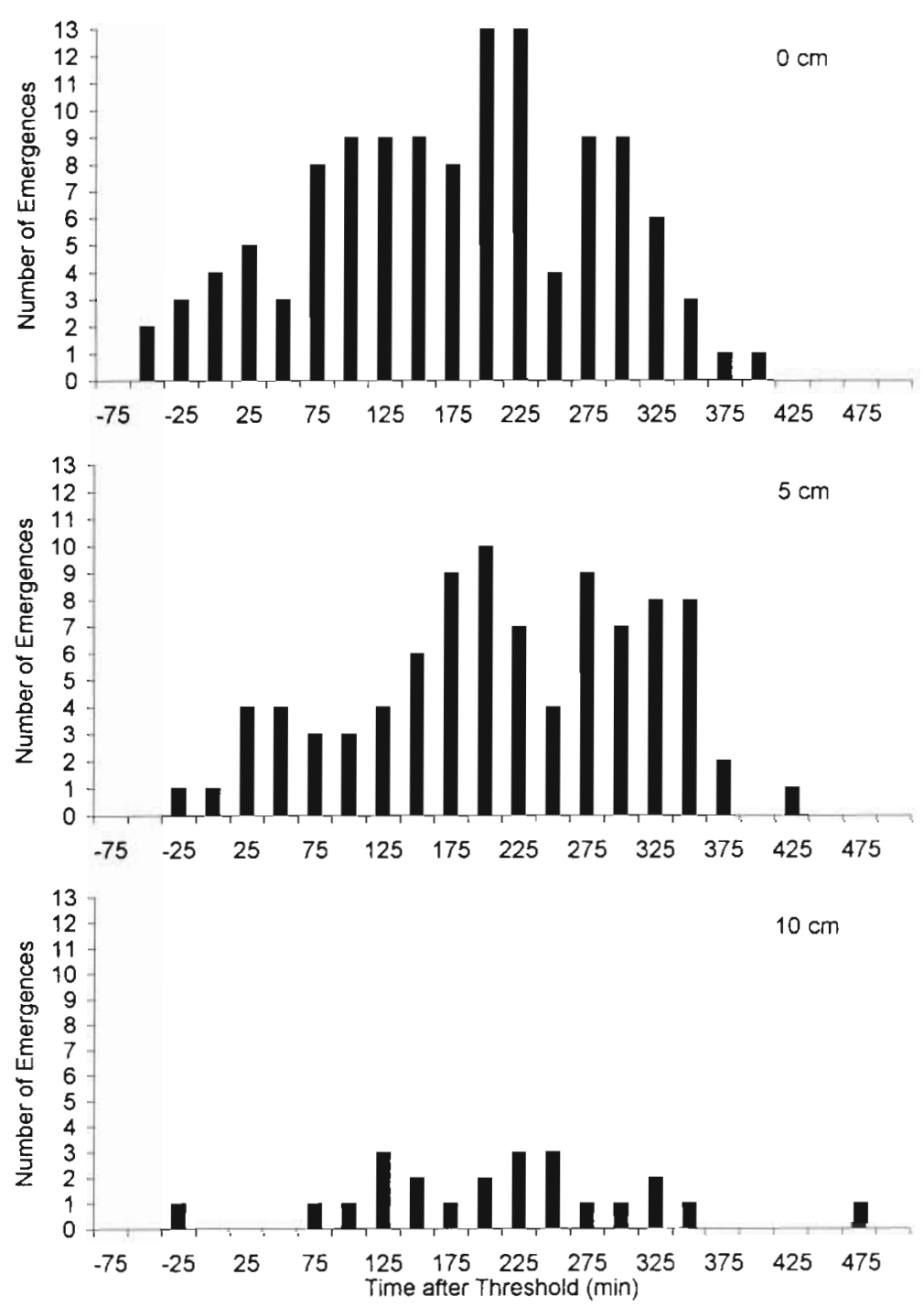

Fig. 3. Relationship between time that the threshold occurred at 0,5 , and $10 \mathrm{~cm}$ in the nest neck and time that emergences occurred $(n=150)$. Time 0 indicates time the threshold was reached

our study $\left(F_{1,149}=3.15, \mathrm{p}=0.078, \mathrm{r}=0.145, \mathrm{n}=150\right)$. In addition, support for the explanation that there is variation in the arrival of hatchling groups at the surface is provided by Witherington et al. (1990), who found that the pattern of hatchling emergences on Melbourne Beach, Florida, assumed a normal distribution between 19:30 and 06:30 h, with a peak between 23:00 and 24:00 h.

Temperatures above a critical threshold could cue hatchlings, either by physiologically inhibiting hatchlings, or by representing a dangerous environment above the sand without physically affecting hatchlings. In the first case, hatchlings play a passive role in initiating emergence because they are able to emerge only when the temperature is cool enough for them to move. In the second case, the cue is behavioral; hatchlings must associate a safe emergence with a particular temperature. The first case is more probable, because emergence patterns can be explained more simply through physiological inhibition than through behavioral mechanisms.

Studies of upper thermal tolerances of sea turtle hatchlings have revealed that above $28.5^{\circ} \mathrm{C}$ in green turtles (Mrosovsky 1968) and $33.0^{\circ} \mathrm{C}$ in loggerheads (O'Hara 1980) coordinated swimming activity ceases. Mrosovsky (1968) related the upper thermal tolerance of swimming green turtle hatchlings to the thermal threshold of emerging hatchlings based on temperatures recorded at a depth of $2 \mathrm{~cm}$ in 2 emerging nests. His reported threshold of $28.5^{\circ} \mathrm{C}$ is much lower than the threshold temperatures at our depths of 0 and $5 \mathrm{~cm}$. O'Hara (1980) conducted his study on Florida loggerhead hatchlings, and his threshold of $33.0^{\circ} \mathrm{C}$, above which hatchling swimming activity was disrupted, was similar to our threshold at $0 \mathrm{~cm}$ in the nest neck $\left(32.4^{\circ} \mathrm{C}\right)$. Witherington et al. (1990) also found that $97 \%$ of loggerhead hatchlings on a Florida beach emerged when temperatures at $5 \mathrm{~cm}$ in the nesting area were below $33^{\circ} \mathrm{C}$. That temperature is similar to our threshold at a depth of $5 \mathrm{~cm}$ in the array adjacent to the nest $\left(33.9^{\circ} \mathrm{C}\right.$ i Moran 1998$)$.

Based on his observations of green turtle hatchlings, Hendrickson (1958) believed that, 'upon encountering temperatures much above $33^{\circ} \mathrm{C}$, the hatchlings cease activity in their escape chamber.' Bustard (1972) hypothesized that green turtle hatchlings did not emerge above a threshold of approximately $31^{\circ} \mathrm{C}$, a value lower than our lowest threshold. Unfortunately, neither Hendrickson nor Bustard clarified the depth at which they measured temperatures or the number of nests in which they monitored hatchling activity. However, the threshold given by Hendrickson for green turtles is more similar both to the threshold presented by O'Hara (1980) and to our values for loggerheads than to that of Mrosovsky. Perhaps the data that Mrosovsky (1968) obtained from only 2 emerging nests were not sufficient to determine the threshold above which hatchlings do not emerge. Because hatchlings change their thermal environment in the nest neck, critical thresholds determined using temperatures taken adjacent to sea turtle nests might not be accurate. 
Changes in relative sand temperatures at different depths may give hatchlings information about their external environment. Hatchlings may interpret a gradient shift from hot upper sand and cool lower sand to cooler upper sand and warmer lower sand as a signal that night is approaching. In a study of emergence patterns in green turtle hatchlings on Heron Island, Australia, Gyuris (1993) observed emergences over seven $24 \mathrm{~h}$ periods and compared her observations with patterns of emergences expected in response to either a threshold or a gradient reversal. She concluded that the hatchling emergence pattern on Heron Island was more similar to a pattern predicted by response to a gradient reversal than to a threshold. Visual inspection of Figs. 3 $\& 4$ reveals that more hatchlings emerged in the $100 \mathrm{~min}$ after the threshold was reached than in the 100 min after the gradient reversal occurred. No particular temperature differential between gradient reversal depths seems to prevent hatchlings from emerging (Fig. 5). The extent to which temperatures have reversed is apparently not a cue.

One possible reason for the dissimilarity between our results and those of Gyuris is that the studies involved hatchlings of different sea turtle species. In addition, our study was conducted over the span of $2 \mathrm{mo}$, instead of $2 \mathrm{wk}$, so that emerging hatchlings were exposed to a variety of thermal regimes over the season. Thermocouples in our study were also placed directly into the nest neck instead of in a randomly chosen location in the nesting area; this facilitated more accurate monitoring of the hatchling environment. However, our study revealed similar patterns of hatchling emergence in response to gradient reversals in both neck and adjacent thermocouples (Moran 1998).

Rate of temperature decline

The third hypothesis regarding thermal cues suggests that hatchlings emerge in response to a rapid decrease in temperature, presumably indicating sunset. This cue can only apply to upper layers of sand (i.e. depths of $10 \mathrm{~cm}$ or less), because when the sun sets and upper sand cools, deeper sand temperatures remain constant or increase slightly, and do not begin to drop slowly until a few hours later. Rate of temperature decline might be an easy cue for hatchlings to use
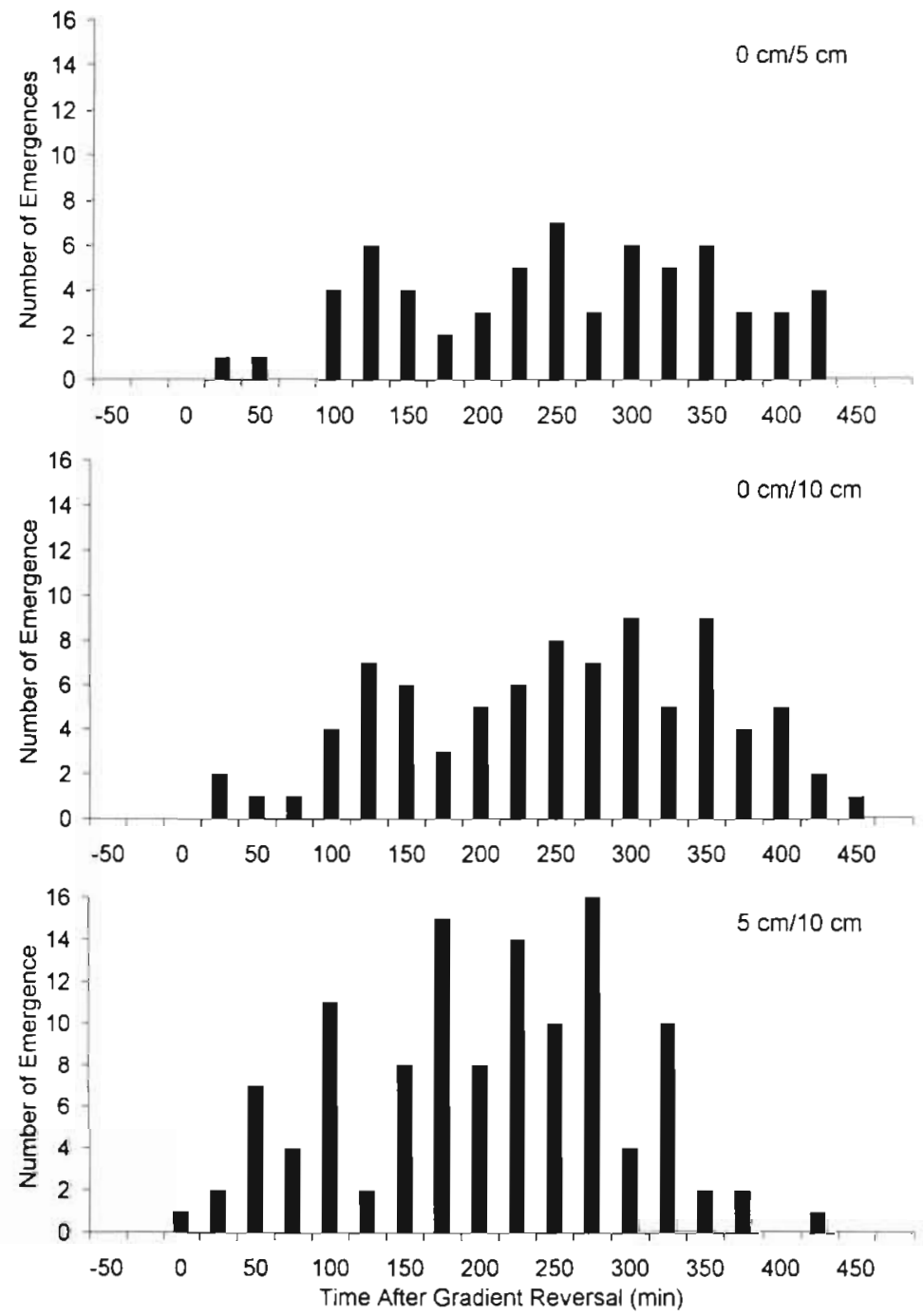

Fig. 4. Relationship between time that the gradient reversal occurred between 0 and 5,0 and 10 , and 5 and $10 \mathrm{~cm}$ in the nest neck and time that emergences occurred $(n=150)$. Time 0 indicates time of gradient reversal

because rapid decreases in temperature are easier to detect than subtle declines. However, rate would probably not be used as the only cue because only hatchlings waiting at or near the surface during the day would feel that rapid temperature decline. Hatchlings ascending later at night when layers of sand are no longer cooling rapidly would have to rely on another cue to ascertain whether they have reached a hospitable thermal environment.

No rapid rate of decline was seen in our nests within the $2 \mathrm{~h}$ prior to emergence. If there was a drastic decrease in temperature, it occurred more than $2 \mathrm{~h}$ prior to emergence, possibly because of the presence of buildings directly behind the beach that shaded the nests (Mrosovsky et al. 1995). If a rate of decline was the cue to which hatchlings responded, they delayed 

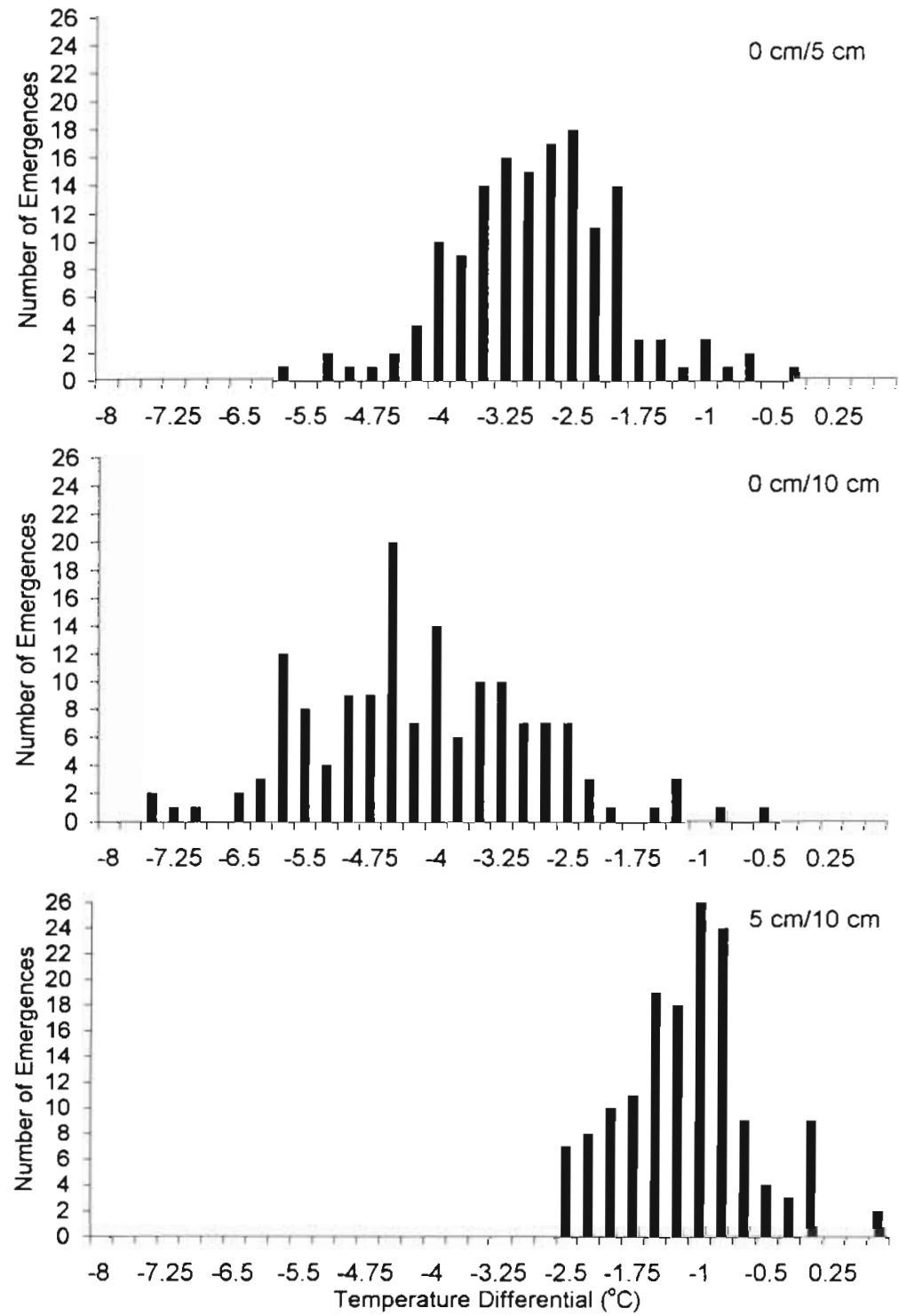

Fig. 5. Relationship between temperature differential between 0 and 5, 0 and 10 , and 5 and $10 \mathrm{~cm}$ in the nest neck and number of emergences occurring at each differential $(n=150)$

their emergence for more than $2 \mathrm{~h}$, a greater delay than that following threshold cues or gradient reversal cues. Because of the lack of a dramatic rate of decline prior to emergence, it was probably not an important cue for hatchlings.

\section{Comparisons with natural nests}

Potential impacts of relocation on hatchling activity should be considered, especially during studies involving the thermal nest environment. Differences between emergences from relocated and natural nests may be expected if sand in the 2 types of nests has dif- ferent thermal properties, moisture content, or grain size. Differences in sand compaction or composition may also impact hatchling emergence (Crain et al. 1995). Relocated nests into which sand has been packed more loosely may result in hatchlings emerging earlier in the evening or in smaller groups because their ascent is not as difficult.

Effect of relocation on nests is difficult to quantify. In 1996, we attempted to evaluate thermal cues in natural in situ nests in Melbourne Beach, Florida. Despite high nesting density in that area, it proved logistically impossible to collect data on sufficient numbers of nests to compare the hypotheses. Therefore, the next year, we moved our study to hatcheries in Broward County. However, data collected from 12 in situ nests in Melbourne Beach in 1996 (Moran 1998) are consistent with results obtained from the study reported here.

\section{Other possible emergence cues}

Temperature is not the only factor that hatchlings could use to time their emergence. Another environmental factor that hatchlings may use is light. Because hatchlings are more vulnerable to predation during the day, there is strong selective pressure for them to wait until dark before emerging. Waiting for darkness also helps hatchlings emerge into an acceptable thermal environment. Evidence indicates, however, that hatchlings do not emerge based solely on the presence or absence of light. Hatchlings have been observed emerging while it is light (Witzell \& Banner 1980), sometimes in the middle of the afternoon (pers. obs.). Some daytime emergences occur during or after rainshowers (Witherington 1986) that lower sand temperatures. Also, it is unlikely that hatchlings are negatively phototaxic as they wait in the sand, and then become positively phototaxic moments later as they use natural lighting to help them find the sea.

Hatchlings could also time their emergence by regulating the timing of their departure from the nest chamber. Hatchlings waiting at the surface are vulnerable to predators. Therefore, a mechanism by which hatchlings reach the surface during nighttime hours would be advantageous. Hatchlings may respond to a cue in the nest itself when they begin their ascent. 
increasing their chances of reaching the surface at an appropriate time.

Such a cue may be thermal or developmental in nature. Hatchlings may use temperature changes at nest depth to gauge corresponding surface temperatures. For example, by beginning their ascent when nest temperatures are lowest, hatchlings may reach the surface when surface temperatures are lowest. Temperatures at depths of 25 and $30 \mathrm{~cm}$ are lowest between 09:00 and 12:00 h (Neville et al. 1988, Mrosovsky \& Provancha 1989). Depending on the length of time required for hatchlings to move from the top of the nest chamber to the sand surface, hatchlings that begin their ascent at noon may reach the surface at night. No evidence exists that time of night when hatchlings emerge is critical to their safety, as long as they emerge after dark. Temperature differences between nests and sensitivity variation among hatchlings could result in a roughly normal temporal distribution of emergences from a single beach over the course of a night or a season, as seen in Witherington et al. (1990).

Hatchlings might also use developmentally-based cues to time their ascent. Preovipositional development is suspended in sea turtle embryos at or near Miller's 6th stage of blastopore development (Miller 1982) and resumes following oviposition. Because loggerheads nest at night, reinitiation of hatchling development also begins at night. Deposition could trigger a biological clock, which might act as the endogenous component of their circadian rhythm. Post-emergent green turtle hatchlings have been shown to exhibit circadian rhythms in swimming activities (Dalton 1979) and might also rely on those rhythms, in the absence of exogenous cues, to time their departure from the nest chamber.

\section{Conservation implications}

Effects of the thermal environment on hatchling emergence may have important management implications in relocated nests. Thermal influence on hatchling emergence may also be important on renourished beaches. Renourishment involves addition of sand to beaches in an attempt to alleviate erosion and has been widely used on Florida's beaches (Crain et al. 1995). New non-native sand on
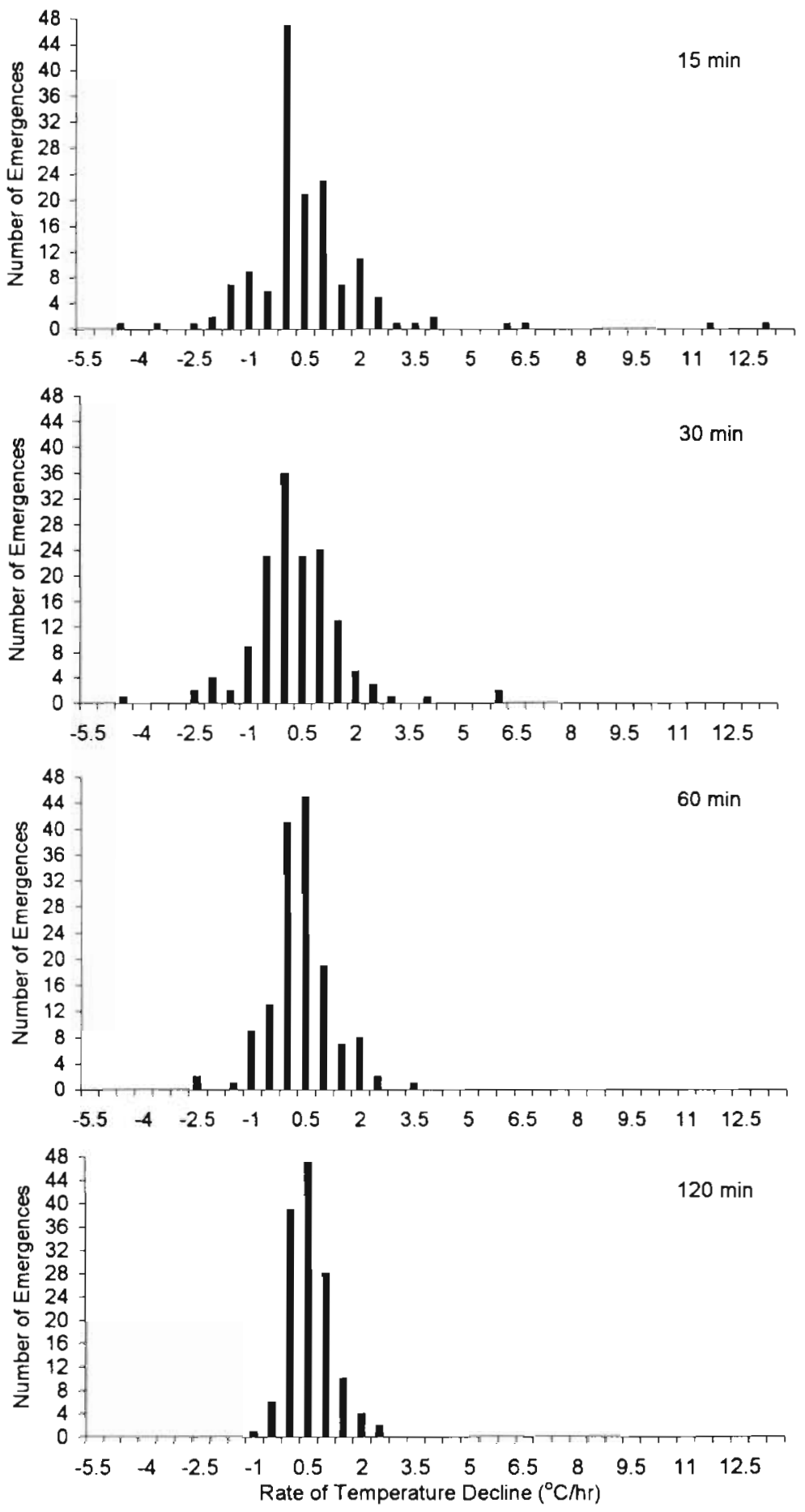

Fig. 6. Relationship between rate of temperature decline at $5 \mathrm{~cm}$ and number of emergences occurring at each rate of decline in the nest neck ( $\mathrm{n}=$ 150). Rates are presented for $15,30,60$, and $120 \mathrm{~min}$ prior to emergence

renourished beaches may have different thermal properties due to color, grain size, moisture content, and composition. For example, Bahamian aragonite sand lowered nest temperatures on a Florida beach by as much as $2.4^{\circ} \mathrm{C}$ and lengthened incubation times of log- 
gerhead nests by as much as $10 \mathrm{~d}$ (Schulman et al. 1994). Cooler beaches could cause hatchlings to emerge at inappropriate times, unless hatchlings also use visual cues.

Knowledge of effects of temperature on the temporal pattern of emergence is also necessary when evaluating effects of beach development for human use. The presence of shade from large buildings, such as condominiums, can result in daily mean temperatures that are $1^{\circ} \mathrm{C}$ lower at a depth of $30 \mathrm{~cm}$ than unshaded sections of beach (Mrosovsky et al. 1995). Such decreases in temperature could have an impact, not only on timing of hatchling emergence, but also on sex ratios of hatchlings (Mrosovsky \& Yntema 1980).

\section{CONCLUSIONS}

A critical threshold temperature exists above which hatchlings do not emerge. Most hatchlings emerge after a reversal in the thermal gradients between sand depths, but no particular temperature differential exists between those depths that cues emergence. A delay occurs after both threshold and reversal cues before hatchlings emerge, which may protect hatchlings under rapidly changing environmental conditions. Most hatchlings emerged sooner after the threshold temperature was reached than after the temperature gradient was reversed, but the 2 cues cannot be completely distinguished without further research.

The threshold and gradient reversal cues may not be mutually exclusive. Gradient reversals in the upper layers of sand may act in conjunction with a threshold temperature as a combined cue. Once the appropriate gradient reversal has occurred, indicating a thermal trend, hatchlings may wait until the temperature falls below a critical level before emerging. Some degree of redundancy in thermal cues could help to protect hatchlings from dangerously high temperatures. However, it may also be simply coincidental that by the time the threshold temperature has been reached, gradient reversals in the upper layers of sand have already occurred. After consideration of both the threshold and gradient reversal hypotheses, we conclude that the most probable mechanism for controlling time of emergence is physiological - that is, a thermal inhibition of coordinated muscle movement so that emergence from the sand is only possible below a critical temperature threshold

Acknowledgements. The Broward County Sea Turtle Conservation Program, L. Fisher, B. Margolis, C. Burney, and L. Ehrhart supplied logistical support and access to the field sites. S. Bouchard, L. Conway-Cranos, A. Deutsch, P. Eliazar, B. Gilmore, K. Guzman, D. Holmes, R. LeBlanc, J. Moran, M. Podolnick, E. Schlanger, M. Tiwari, K. Weir, and D. Wood assisted in data collection. L. Chapman offered advice and support at many stages of this study. C. Lanciani provided constructive comments on this manuscript. All work was in full compliance with the Institutional Animal Care and Use Committee of the University of Florida and all necessary research permits were obtained. Financial support was provided by the Archie Carr Center for Sea Turtle Research and Department of Zoology at the University of Florida, and by grants to K.L.M. from the PADI Foundation and the International Women's Fishing Association.

\section{LITERATURE CITED}

Balazs GH, Ross E (1974) Observations on the preemergence behavior of the green turtle. Copeia 1974:986-988

Bustard HR (1967) Mechanism of nocturnal emergence from the nest in green turtle hatchlings. Nature 214:317

Bustard HR (1972) Australian sea turtles: their natural history and conservation. Collins, Sydney

Caldwell DK (1959) The loggerhead turtles of Cape Romain, South Carolina. Bull Fla Mus Nat Hist Biol Sci 4:319-348

Carr A, Ogren L (1960) The ecology and migrations of sea turtle, 4. The green turtle in the Caribbean Sea. Bull Am Mus Nat Hist 121:1-48

Crain DA, Bolten AB, Bjorndal KA (1995) Effects of beach nourishment on sea turtles: review and research initiatives. Restor Ecol 3:95-104

Dalton SA (1979) Temporal patterns of locomotor activity in hatchling sea turtles. PhD dissertation, University of Florida, Gainesville

Dodd CK Jr (1988) Synopsis of the biological data on the loggerhead sea turtle Caretta caretta (Linnaeus 1758). US Fish Wildl Serv Biol Rep 88:1-110

Godfrey MH, Barreto R, Mrosovsky N (1997) Metabolicallygenerated heat of developing eggs and its potential effect on sex ratio of sea turtle hatchlings. J Herpetol 31 $616-619$

Gyuris E (1993) Factors that control the emergence of green turtle hatchlings from the nest. Wildl Res 20:345-353

Hays GC, Speakman JR, Hayes JP (1992) The pattern of emergence by loggerhead turtle (Caretta caretta) hatchlings on Cephalonia, Greece. Herpetologica 48:396-401

Hendrickson JR (1958) The green turtle, Chelonia mydas (L.) in Malaya and Sarawak. Proc Zool Soc Lond 130:455-535

Maloney JE, Darian-Smith C, Takahashi Y, Limpus CJ (1990) The environment for development of the embryonic loggerhead turtle (Caretta caretta) in Queensland. Copeia 1990:378-387

Miller JD (1982) Embryology of marine turtles. PhD dissertation, University of New England, Armidale

Moran KL (1998) Effects of the thermal environment on the temporal pattern of emergence of hatchling loggerhead turtles (Caretta caretta). MS thesis, University of Florida, Gainesville

Mrosovsky $N$ (1968) Nocturnal emergence of hatchling sea turtles: control by thermal inhibition of activity. Nature 220:1338-1.339

Mrosovsky N, Provancha J (1989) Sex ratio of loggerhead sea turtles hatching on a Florida beach. Can J Zool 67: 2533-2539

Mrosovsky N, Yntema CL (1980) Temperature dependence of sexual differentiation in sea turtles: implications for conservation practices. Biol Conserv 18:271-280

Mrosovsky N, Lavin C. Godfrey MH (1995) Thermal effects of condominiums on a turtle beach in Florida. Biol Conserv $74: 151-156$

Neville A, Webster WD, Hendricks EL, Hendricks I, Marvin 
G, Marvin WH, Gouveia JF (1988) The effects of nest temperature on hatchling emergence in the loggerhead sea turtle (Caretta caretta). In: Schroeder B (compiler) Proceedings of the 8th Annual Workshop on Sea Turtle Conservation and Biology. NOAA Tech Mem NMFS-SEFC214. $p 71-73$

O'Hara J (1980) Thermal influences on the swimming speed of loggerhead turtle hatchlings. Copeia 1980;773-780

Schulman AA, Milton SL, Lutz PL (1994) Aragonite sand as a nesting substrate and its effect on Caretta caretta nests. In: Bjorndal K, Bolten A, Johnson D, Eliazar P (compilers) Proceedings of the 14 th Annual Symposium on Sea Turtle Biology and Conservation. NOAA Tech Mem NMFSSEFSC-351, p 134

Stancyk SE (1982) Non-human predators of sea turtles and their control. In: Bjorndal KA (ed) Biology and conserva-

Editorial responsibility: Otto Kinne (Editor), Oldendort/Luhe, Germany tion of sea turtles. Smithsonian Institution Press, Washington, DC, p $139-152$

Witherington BE (1986) Human and natural causes of marine turtle clutch and hatchling mortality and their relationships to hatchling production on an important Florida nesting beach. MS thesis, University of Central Florida, Orlando

Witherington BE, Bjorndal KA, McCabe CM (1990) Temporal pattern of nocturnal emergence of loggerhead turtle hatchlings from natural nests. Copeia 1990:1165-1168

Witzell WN, Banner AC (1980) The hawksbill turtle (Eretmochelys imbricata) in Western Samoa. Bull Mar Sci 30: 571-579

Yeager DP, Ultsch GR (1989) Physiological regulation and conformation: a BASIC program for the determination of critical points. Physiol Zool 62:888-907

Submitted: February 2, 1999; Accepted: June 6, 1999 Proofs received from author(s): October 28, 1999 